\title{
PARADOXES OF HUMAN COGNITION
}

\begin{abstract}
This paper presents the main paradoxes of the theory of human cognition, namely the paradoxes of epistemology and methodology. Each of paradoxes is given its laconic solution using a more strict definition of relevant concepts. Suggested solutions could be helpful in developing further the complete teaching of human cognition.
\end{abstract}

Keywords: human cognition, philosophy, truth, proof, contradiction, paradoxes of epistemology, paradoxes of methodology.

Introduction. Søren Kierkegaard has suggested a paradoxical interpretation of the notion of paradox: "the thinker without the paradox is like the lover without passion". As all the negative statements this beautiful aphorism does not reveal any positive feature of its subject. In sciences the term paradox is strongly connected to self-contradiction or a contradiction to well established facts and general statements. A classical example of selfcontradiction is presented by "The liar" paradox. The opposition to "apparent" facts usually emerge by the discovery of revolutionary theories like relativistic mechanics and quantum mechanics.

In regard of paradoxes of science the central point is the following: "Could the paradoxes of science be resolved?" Philosophers gave very different answers to this question, especially considering Zeno's aporias. Learning about Zeno's aporias Aristotle without hesitation took up the challenge and suggested his solutions of the so called "aporias of motion" though some of Aristotelian argu- ments were quite difficult to conceive. For instance, commentators are divided in their understanding of Aristotle's analysis of the so called aporia "Stadion" (Physics, 69 239b33).

Quite unexpectedly Immanuil Kant who assessed laws of formal logic as evidence of absolute truth made an exception for contradiction ("antinomies") of reason. His daring mind even suggested proofs in regard of the infinity of the world space and time. Yet modern time analysis revealed certain flows in Kant's argumentation like using incompatible substantial and relativistic conceptions of space and time (Djidjian, 2004, pp. 174-185).

The great system builder Georg Hegel extended Kantian liberal attitude to logical contradictions believing that just "the contradiction is the root of all movement and vitality; it is only in so far as something has a contradiction within it that it moves, has an urge and activity."

The $20^{\text {th }}$ century greatest mathematician David Hilbert categorically denied the very existence of paradoxes: "The true reason why 
no one has succeeded in finding an unsolvable problem is, in my opinion, that there is no unsolvable problem. In contrast to the foolish Ignorabimus, our credo avers: We must know, we shall know" (Dawson, 1997).

Understanding paradoxes requires an adequate knowledge of the essence of the truth and its negation - the false. We follow Aristotelian fundamental definition "Truth is the adequacy of the thought and reality." And since the concept of the truth lies in the bases of the "The liar" paradox we start just its analysis.

I would like to mention also that the main principle of our approach to any kind of contradictions and paradoxes is that all of them could be solved by a certain correction of relevant concepts.

\section{Pardoxes of epistemology}

\section{The "absolute lire" paradox}

An ancient philosopher Epimenides declared: "I am a liar".

Thesis. Epimenides' statement "I am a liar" is true. Then Epimenides is a liar. Then his statement is false.

Anti-thesis. Epimenides' statement “I am a liar" is false. Then Epimenides, according to the content of his statement, is not a liar and so must be a truth-teller. So his statement is true.

Solution. The above Thesis presumes that liars say only false things, or in other words, it presumes the notion of the absolute liar. Similarly, the above Anti-thesis presumes that a truth-teller says only true things, or in other words, it presumes the notion of the absolute truth-teller. But in reality there are no absolute liars and no absolute truth tellers.

\section{The fundamental lire-paradox}

Epimenides declared: "I am lying now" and did utter not utter any other word.

This fundamental version of the lire-paradox has the following contemporary formulation also: ("The sentence in these brackets is false").

To analyze the fundamental lire-paradox let us denote the sentence in these brackets as A. Thesis. The sentence A ("The sentence in these brackets is false") is true. Then according to its content $\mathrm{A}$ is false.

Anti-thesis. The sentence A ("The sentence in these brackets is false") is false. Then according to its content the sentence A is true.

Solution. From the days of Medieval logicians it is well known that the fundamental lireparadox is caused by its self-referential nature: the sentence A speaks about itself. For excluding this type of paradoxes we have to deny using self-referential sentences and expressions.

\section{Senses versus ratio paradox}

Thesis. Ratio and thinking without sensual data are empty, out of any subject matter (Kant, 1781).

Anti-thesis. Scientific knowledge is the knowledge of general which can be provided only by ratio.

Solution. Senses provide the elementary units of knowledge from which human ratio composes general concepts. 


\section{Empirical versus theoretical paradox}

Thesis. There could be no knowledge without empiric cognition and practice.

Anti-thesis. The human understanding of the world is provided by scientific theories.

Solution. Empiric knowledge is the basic level of human understanding, its highest level being provided by scientific theories.

\section{Relative truth versus absolute truth}

Thesis. Truth is the adequacy of the thought and reality (Metaphysics 63 1027b20). This adequacy can't be absolute, it can be only relative.

Anti-thesis. Laws of logic and postulates of mathematics are examples of necessary, absolute truth (Kant, 1781). One can't imagine a world where the postulates of Euclidean geometry are inconsistent.

Solution. After the emergence and acceptance of the non-Euclidean geometry and mathematical logic in the second half of the $19^{\text {th }}$ century, scientists are unable to demonstrate any single case of a theoretical absolute truth. As an adequacy to reality, truth is relative in its very essence (Plank, 1949).

\section{Apriori versus aposteriori}

Thesis. From the times of Aristotle scientific knowledge is considered necessary and general. No experience can guarantee the necessary nature of its conclusions (Hume, 1777). The necessary can't be dependent on experience. It could be only apriori.

Antithesis. Scientific knowledge should be true; any scientific statement should be checked by experience and experiment. Thus the truth of scientific knowledge follows from experience, truth is aposteriori.

Solution. In times of absolute dominance of Euclidean geometry, Kant's conception of apriori was the only possible explanation of the existence of the absolutely true human knowledge. And on the contrary, since the acceptance of the consistency of nonEuclidean geometry (Riman, 2004) there remained no need in the concept of apriori.

\section{Mathematical proof versus mathematical truth}

Thesis. The strength of mathematical knowledge is in its proof. Proof is the truth of mathematics (Hilbert, 2004).

Anti-thesis. Mathematical knowledge has such an abstract level that mathematical truth is never checked by experience, empirically.

Solution. Though a highly abstract science, geometry's adequacy to reality, the choice between Euclidean geometry and nonEuclidean geometry could be made at galactic distances.

\section{Conventionalism versus} progressiveness

Thesis. The revolutionary theories of theoretical physics in the first decades of the $20^{\text {th }}$ century were in such a contrast to human experience and common sense that the transition from an old (classical) theory to a radically new theory could be conceived just as a convention between leading, prominent scientists later extended to the whole scientific community (Poincare, 1946).

Anti-thesis. Learning the history of sciences one could not miss that science keeps con- 
stantly progressing, and that just by the transition from an old (classical) theories to the better ones.

Solution. New radical theories come to life by the discovery of radically new levels of the nature that require radically new ideas contrasting ordinary experience and common sense. Changes of theories follow the need of better description of reality but never are accepted by convention.

\section{Human cognition versus animal cognition}

Thesis. Only humans think rationally. All animal behavior is instinctive, genetically inherited.

Anti-thesis. Higher animals demonstrate a wide range of learned, non-instinctive behavior (Darwin, 1874).

Solution. Human cognition is rational, abstract, and verbal. Animals possess different levels of sensual cognition based on the ability of generalization by sense-perception (Diener et al., 2006).

\section{Reason versus judgment}

Thesis. The highest level of human cognition is provided by human reason. Judgment is non-productive and only provides simple, logical solutions (Hegel, 1969).

Anti-thesis. Thinking and cognition are functions of human brain, yet there is no evidence of the existence of separated brain-sections for reason or judgment.

Solution. If we define human judgment as the ability to prove, while reason - as the ability of research (by solving problems and finding answers to questions), then we can presume human brain having a separate algorithm for proofs and another algorithm - for research. But nothing can prevent considering these two algorithms as the main parts of the general algorithm of human cognition.

\section{Consciousness versus self-conscience}

Thesis. Consciousness is that mental wholeness which is responsible for all processes of human cognition including that of selfcognition and self-conscience.

Anti-thesis. Self-conscience is the main attribute of human cognition that separates humans from the animal world.

Solution. Self-conscience is just the ability of a living organism to cognize its own separate being in the surrounding world. Theoretically, nothing could prevent or forbid animals to have an ability of cognizing their own separate being. The social relations in chimp tribes in this sense are identical to that of human social life.

\section{Conscious versus subconscious} and unconscious

Thesis. In Freud's conception, subconscious is the lowest level of consciousness governed by instinctive desires, including the sexual and anti-social deviations (Jung, 1964).

Subconscious by Henri Poincare is the function of the part of human brain busy with production of creative ideas (Poincare, 1946). The process of production of new ideas is that of making combinations of simple ideas the best of which are pushed to the conscious level as creative solutions. 
Anti-thesis. By Freud, subconscious is the set of units containing instinctive desires. As desires - be it conscious or unconscious - they have no connection to cognitive processes.

By Henri Poincare, subconscious thinking presumes a hypothetic mechanism of producing new ideas as combinations of simple ideas that, in his own words, can't work independent of conscious thinking. Even so, after almost hundred years that past after Poincare's report his hypothesis has never been confirmed.

Solution. All human ideas including the so called creative ones are produced by conscious analysis of problematic situations followed by hypothetical syntheses of ideas of solutions.

\section{Paradoxes of methodology}

\section{The paradox of the universal method}

Thesis. The history of science proves that each scientific discovery has been made by its own exceptional, unordinary way (Whewel, 1864).

Anti-thesis. There are many powerful general methods of scientific investigation like analysis and synthesis, induction and deduction, experimenting and modeling, idealization and formalization, etc., which work effectively in all branches of sciences. So uniting these general methods into one logical structure would provide science the universal method of research and investigation.

Solution. All general methods of scientific investigation are the structural parts of the universal method of scientific research. And this universal method is the method of hypotheses.

\section{Hypothesis versus proof}

Thesis. Any scientific idea is born as hypothesis, as a hypothetical solution of a problematic situation.

Anti-thesis. Mathematical knowledge is comprised of strictly proved theorems, and there is no place for hypotheses in the kingdom of mathematics.

Solution. Any theorem as a mathematical statement is a mathematical hypothesis before it eventually gets its proof.

\section{Scientism versus hermeneutics}

Thesis. Scientism as the theoretical-experimental model of building scientific teachings is the only reasonable model for all branches of science.

Anti-thesis. The main task of humanities should be understanding individuals and their groups, revealing their interests and intentions while the task of natural sciences is explaining natural phenomena (Wright, 1971).

Solution. There could be no explanation of a natural phenomenon without its understanding. In its turn, understanding interests and intensions of people helps to explain the events of the past. The special feature of social phenomena is the immense number of acting factors and their instability.

\section{The whole versus its parts}

Thesis. To know the whole we have to investigate its parts (Heidegger, 1962).

Anti-thesis. To know the parts we need certain knowledge of the whole (Heidegger, 1962).

Solution. The knowledge of the whole helps investigating the parts, and the investigation 
of the parts enriches the knowledge of the whole.

\section{Creativity versus standards}

Thesis. The true values in science, technology, and arts are produced only by creative thought.

Anti-thesis. Technology can't function without standards; the most valuable results in science are those that provide methods (algorithms) for standard solutions of problems.

Solution. Any new idea is a creative solution. Creativity is often a new way of using standards.

\section{Insight versus logic}

Thesis. The only way to discovery is the momentary insight into the true essence of the problem under investigation.

Anti-thesis. There can be no solution of any theoretical problem without logical reasoning.

Solution. Logical reasoning is the necessary basis of problem solving while insight is the crowning moment of the logical search for the winning idea.

\section{Analysis versus synthesis}

Thesis. The unity of the analysis and synthesis is one of the most powerful means of research and problem solving.

Annti-thesis. Analysis is the precondition of problem solving yet synthesis is a higher level of scientific thinking.

Solution. Problem analysis is the first phase of problem solution procedures providing the best condition for effectiveness of the second phase - the synthesis of the idea of solution (Djidjian, 1984; Djidjian, 2004).

\section{The paradox of analogizing}

Thesis. Analogy is the weakest form of logical inference.

Anti-thesis. As history of science confirms, scientific discoveries have been made helped by analogies (Mach, 1905).

Solution. Each new idea is synthesized by analogy with the solution of a similar prototype problem. (Djidjian, 1984; Djidjian, 2004).

\section{Talent versus geniality}

Thesis. Talent is gained by learning while geniality is inborn.

Anti-thesis. Genius is self-made while talent is inborn.

Solution. Three greatest geniuses of science Einstein, Darwin, and Mendel never demonstrated problem solving qualities higher than ordinary ones. So we know geniuses of science not by their extraordinary intellectual capacities but by their fruits - their great revolutionary conceptions. Talents are known from the early childhood by their extraordinary problem-solving abilities which presume inborn great mental capacities (Djidiian, 2002).

\section{The paradox of intuition}

Thesis. The greatest scientists have usually prescribed their discoveries to scientific intuition though not being able to point out its content and essence (Descartes, 1637; Bunge, 1962). 
Anti thesis. It is impossible making discoveries not having the following cognitive components - a sufficient level of inborn mental capacities, a sufficient scope of knowledge in the given field of research, a sufficient level of own problem-solving experience in the given field of research.

Solution. Scientific intuition is the unity of the above mentioned cognitive components - a sufficient level of inborn mental capacities, the scope of knowledge, and own personal problem-solving experience. So every scientist has as stronger intuition as stronger capacities, relevant knowledge, and personal experience he has got, the latter being the most important component (Djidjian, 1984; Djidjian, 2004).

\section{The paradox of Gödel's theorem}

Thesis. Gödel's formula $A_{p}(p)$ is undecidable in the system of formalized arithmetic what means that formalized arithmetic is incomplete (Whitehead \& Russell, 1910-1913; Gödel 1931).

Anti-thesis. The only content of Gödel's formula $A_{p}(p)$ is the following: "The formula $A_{p}(p)$ tells that it is unprovable" (Kleene, 1952). So it is absolutely clear that Gödel's formula $\mathrm{A}_{\mathrm{p}}(\mathrm{p})$ has no mathematical content.

Solution 1. Having no mathematical content, Gödel's formula $A_{p}(p)$ can't support the claim that formalized arithmetic is incomplete.

Solution 2. It is widely accepted that the content interpretation of Gödel's formula - “ $A_{p}(p)$ tells that $A_{p}(p)$ is not provable" - is a selfreferential sentence. So Gödel's proof of the incompleteness of formalized arithmetic can be accepted only by those mathematicians who think that in some branches of mathemat- ics proving theorems would be much more difficult denying the use of self-referential formula (Kleen, 1952). But such an argument should be principally rejected since here the foundations of mathematics are discussed.

Solution 3. Gödel's proof is rigorous due to using his invention of Gödel's numbering (Smith, 2007). But it is not difficult to show that using Gödel's numbering one violates the fundamental law of identity. Certain Gödel's number $\boldsymbol{p}$ in the frame of the same proof is used in two different meanings - as a certain natural number $\boldsymbol{p}$ and as the number of Gödel's formula $A_{p}(p)$.

\section{Conclusions}

Let us review the useful conclusions of the above analysis of the paradoxes of epistemology and methodology of human cognition.

Senses provide the elementary units of knowledge from which human ratio composes general concepts.

Empiric knowledge is the basic level of human understanding, its highest level being provided by scientific theories.

As an adequacy to reality, truth is relative in its very essence.

Kant's conception of apriori was the only possible explanation of the existence of the absolutely true human knowledge. Nowadays the acceptance of the consistency of nonEuclidean geometry abolishes the concept of apriori.

Geometry's adequacy to reality, the choice between Euclidean geometry and nonEuclidean geometry could be made at galactic distances.

New radical theories come to life by the discovery of radically new levels of the nature 
that require radically new ideas contrasting ordinary experience and common sense.

Animals possess different levels of sensual non-verbal cognition based on the ability of generalization by sense-perception.

We define human judgment as the ability to prove, while reason - as the ability of research yet nothing can prevent considering them as the main abilities of the general human cognition.

Self-conscience is just the ability of a living organism to cognize its own separate being in the surrounding world. Theoretically nothing could prevent or forbid animals to have an ability of cognizing their own separate being.

All human ideas including the so called creative ones are produced by conscious analysis of problematic situations followed by hypothetical syntheses of ideas of solutions.

All general methods of scientific investigation are the structural parts of the universal method of scientific research. And this universal method is the method of hypotheses.

Any theorem as a mathematical statement is a mathematical hypothesis before it eventually gets its proof.

There could be no explanation of a natural phenomenon without its understanding. In its turn, understanding interests and intensions of people helps to explain the events of the past.

Creativity is often a new way of using standards.

Logical reasoning is the necessary basis of problem solving while insight is the crowning moment of the search for the winning idea.

Problem analysis is the first phase of the problem solution providing the best condition for effectiveness of the second phase - the synthesis of the idea of solution.

Each new idea is synthesized by analogy with the solution of a similar prototype problem.

We know geniuses of science not by their extraordinary intellectual capacities but by their fruits - their great revolutionary conceptions. Talents are known from the early childhood by their extraordinary problemsolving abilities which presume inborn great mental capacities.

Scientific intuition is the unity of inborn mental capacities, the scope of knowledge, and own personal problem-solving experience, the latter being the most important component.

Gödel's theorem does not prove the incompleteness of formalized arithmetic or of anything else.

It is said that science is about that what we know, while philosophy - about that what we do not know. The above solutions of paradoxes of human cognition provide some grounds for the hope that epistemology and methodology departing from philosophizing come closer to science.

\section{REFERENCES}

Aristotle (1949). Prior and Posterior Analytics, (W.D. Ross, Ed.). Oxford: Oxford University Press.

Aristotle (1996). Physics. Oxford: Oxford University Press.

Aristotle (1998). Metaphysics. (H. LawsonTancred, Trans.) Penguin.

Bunge, M. (1962). Intuition and Science. Prentice-Hall. 
Darwin, Ch. (1874). The Descent of Man, and Selection in Relation to Sex (2nd ed.). London: John Murray.

Darwin, Ch. (1958). The Autobiography of Charles Darwin 1809-1882. London: Collins.

Dawson, J.W. Jr (1997). Logical Dilemmas: The Life and Work of Kurt Gödel. Wellesley MA, A.K. Peters.

Descartes, R. (1637). Discourse on the Method, Optics, Geometry and Meteorology, (Revised edition 2001), Indianapolis: Hackett.

Djidjian, R. (1984). Metodologicheskii analiz processa otkrytiya i izobreteniya (Methodological Analysis of the Process of Discoveries and Inventions, in Russian), Yerevan, izdatel'stvo erevanskogo gosudarstvennogo universiteta.

Djidjian, R. (2002). The Secret of Geniality. Yerevan: Noyan Tapan.

Djidjian, R. (2004). Getting Ready for Great Discoveries. Yerevan: Yerevan state university publication.

Djidjian, R. (2011). Building the logic of scientific discoveries. Main Issues of pedagogy and psychology (pp. 164173). №3. Yerevan.

Gödel, K. (1931). Über formal unentscheidbare Sätze der Principia Mathematica und verwandter Systeme, I, Monatshefte für Mathematik und Physik, 38(1), 173-198.

Hegel, G. (1969). Science of Logic. Allen and Unwin.

Hershell, J. (1831). A preliminary discourse on the study of natural philosophy, part of Dionysius Lardner's Cabinet cyclopedia (1831, new edition 1840).
Hilbert, D. (2004). David Hilbert's Lectures on the foundations of Mathematics and Physics, 1891-1933, SpringerVerlag Berlin Heidelberg.

Hume, D. (1748). An Enquiry Concerning Human Understanding. London: A. Millar.

Itlis, H. (1932). Life of Mendel. W.W. Norton \& Company, Inc., London.

Jung, C. (1964). Approaching the unconscious. Man and his Symbols. Doubleday

Kant, I. (1781). Critique of Pure Reason. Cambridge: Cambridge UP, 1998.

Kleene, S. (1952). Introduction to Meta-Mathematics. Amsterdam: North-Holland Publishing Company.

Mach, E. (1905). Erkenntnis und Irrtum. Skizzen zur Psychologie der Forschung. Leipzig: Verlag von Johann Ambrosius Barth.

Mill, J.S. (1843). A System of Logic, Honolulu: University Press of the Pacific, 2002.

Plank, M. (1949). Scientific autobiography. New York: Philosophical Library, 1968.

Poincare, H. (1946). The foundations of science. Washington, D.C.: University Press of America, 1982.

Riemann, B. (2004). Collected papers. Heber City: Kendrick Press.

Smith, P. (2007). An Introduction to Gödel's Theorems. Cambridge University Press.

Whewell, W. (1860). On the philosophy of discovery: chapters historical and critical. London.

Whitehead, A.N., \& Russell, B. (1910-1913). Principia mathematica, Vol. 1-3, 
(1 ed.). Cambridge: Cambridge University Press.

Wright, von G.H. (1971). Explanation and Understanding. Ithaca, Cornell UP, 2004.

Zentall, Th.R., Wasserman, E.A., Lazareva,
O.F., Thompson, R.K., \& Rattermann, M.J. (2008). Concept Learning in Animals. Comparative cognition and behavior reviews, vol. 3, 1345. 